\title{
Successful chondrogenesis within scaffolds, using magnetic stem cell confinement and bioreactor maturation
}

Nathalie Luciani ${ }^{1 *}$, Vicard $\mathrm{Du}^{1}$, Florence Gazeau ${ }^{1}$, Alain Richert ${ }^{1}$, Didier Letourneur ${ }^{3}$, Catherine Le Visage ${ }^{2}$ and Claire Wilhelm ${ }^{1}$

${ }^{1}$ Laboratoire Matière et Systèmes Complexes (MSC), UMR 7057 CNRS \& University Paris Diderot, Paris, F-75205 cedex 13, France

${ }^{2}$ INSERM, U791, LIOAD, Nantes, F-44042, France

${ }^{3}$ Laboratoire de recherche vasculaire translationnelle, INSERM UMR 1148 \& University Paris Diderot, Paris, France.

*Corresponding author: Laboratoire Matière et Systèmes Complexes (MSC), UMR 7057 CNRS \& University Paris Diderot, Paris, F-75205 cedex 13, France. E-mail address: nathalie.luciani@univ-paris-diderot.fr

\section{Statement of significance:}

A combination of several innovative technologies (magnetic cell seeding, polysaccharide porous scaffolds, and dynamic maturation in bioreactor) enabled unprecedented successful chondrogenesis within scaffolds.

\begin{abstract}
Tissue engineering strategies, such as cellularized scaffolds approaches, have been explored for cartilage replacement. The challenge, however, remains to produce a cartilaginous tissue incorporating functional chondrocytes and being large and thick enough to be compatible with the replacement of articular defects. Here, we achieved unprecedented cartilage tissue production into a porous polysaccharide scaffold by combining of efficient magnetic condensation of mesenchymal stem cells, and dynamic maturation in a bioreactor. In optimal conditions, all the hallmarks of chondrogenesis were enhanced with a 50-fold increase in collagen II expression compared to negative control, an overexpression of aggrecan and collagen XI, and a very low expression of collagen I and RUNX2. Histological staining showed a large number of cellular aggregates, as well as an increased proteoglycan synthesis by chondrocytes. Interestingly, electron microscopy showed larger chondrocytes and a more abundant extracellular matrix. In addition, the periodicity of the neosynthesized collagen
\end{abstract}


fibers matched that of collagen II. These results represent a major step forward in replacement tissue for cartilage defects.

Keywords: Magnetic mesenchymal stem cells; Chondrogenesis; Cartilage defect; Bioreactor; Tissue engineering.

\section{Introduction}

Osteoarthritis is a chronic progressive musculoskeletal disorder characterized by a gradual loss of hyaline cartilage. It affects a large number of middle-aged people [1], markedly undermining their mobility, quality of life and productivity, and resulting in significant healthcare spending [2-5]. Because of the low turnover of extracellular matrix components in the avascular environment [6], joint cartilage cannot repair itself. Attempts to repair hyaline cartilage have included microfracture, mosaicplasty and autologous chondrocyte implantation (ACI) [7-9], but the long-term efficacy of these approaches is uncertain [10,11]. Research in this setting has also focused on the capacity of mesenchymal stem cells (MSC) to differentiate into chondrocytes [12, 13], and to secrete growth factors, cytokines and chemokines [14]. Most techniques currently used to trigger in vitro chondrogenesis of MSC share a cell condensation step, currently achieved through centrifugation or micromass culture, as a prerequisite for commitment to the chondrogenic lineage [15]. We recently produced compact, functional cartilaginous tissues of millimeter dimensions by controlling MSC condensation and fusion with magnets [16]. Besides, aggregates of differentiated MSC incorporated into an in vitro model of cartilage defects showed the same mechanical properties (shear stress) as physiological cartilage [17]. MSC sheet engineering has also been explored as a scaffold-free method of cartilage regeneration [18, 19]. Recently, it was shown that MSC can differentiate into three-dimensional pellets in the presence of hyaluronan (HA) microspheres loaded with TGF- $\beta 3$; HA lubricates the joint and provides mechanical support [20]. A scaffold support thus seems necessary to retain therapeutic cells at the target site and to avoid disruption of the replacement cartilage by frictional shear stress [21]. Porous scaffolds can be manufactured from synthetic materials or natural biodegradable polymers [22, 23], and can also act as a drug delivery vehicle [24]. Natural polymers have the added advantages of being biocompatible, facilitating cell adhesion, and differentiation [25]. Scaffolds can be designed with a specific 3D shape and stiffness suitable for use in regenerative medicine. Multiphase osteochondral scaffolds based on collagen- 
glycosaminoglycan and calcium phosphate constructs have already been used to mimic native joint cartilage [26]. However, it has so far proved difficult to induce stem cells to differentiate into chondrocytes and osteocytes when embedded in such scaffolds [27]. One critical parameter is pore size, which must permit both cell condensation and chondrogenic differentiation. The main challenge in seeding a scaffold with cells is to reach a sufficient cell density to achieve a tissue-like cell confinement and organization. To improve cell incorporation, one must use external forces acting on cells at a distance. Magnetic forces are then the most appealing candidates, combining long range action and remote application. Magnetic seeding within scaffold was recently achieved as a valuable strategy to enhance seeding efficacies and to promote cell condensation [28, 29].

In this study, we hypothesized that a magnetic seeding and condensation process, that has already been shown to drive chondrogenesis in absence of a scaffold [16], could be used on seeded scaffolds. We selected hydrophilic, non-immunogenic and biodegradable pullulan and dextran polysaccharides [30]. They are both FDA approved for a wide variety of applications in food and pharmaceutical industries. Several groups previously reported pullulan/dextran hydrogels for in vitro culture and differentiation of stem cells [31-33]. Their interconnected porous architecture allows for homogeneous cell distribution and provides a 3D microenvironment with enhanced diffusion of nutrients and oxygen [34]. Here, we demonstrate that pullulan/dextran scaffolds, previously shown to confine stem cells [35], not only retain MSC but also allow them to differentiate into chondrocytes. Using magnetic forces to attract and retain the cells within the scaffold, we enhanced MSC seeding density and condensation. When we combined this magnetic condensation technology with dynamic differentiation in a bioreactor, MSC differentiation into chondrocytes within the scaffold constructs was markedly improved.

\section{Materials and methods}

\subsection{Anionic maghemite nanoparticles}

Magnetic nanoparticles were synthesized with the Massart procedure, by alkaline coprecipitation of iron chloride salts [36]. The resulting particles have a maghemite core $(\gamma-$ $\mathrm{Fe} 2 \mathrm{O} 3$ ) $8 \mathrm{~nm}$ in diameter and are stabilized in aqueous suspension by adsorption of negatively charged citrate ligands.

\subsection{Cell culture, cell labeling and iron quantification}


Two different batches of human mesenchymal stem cells (MSC, Lonza, Basel, Switzerland) were cultured in MSCGM medium (Lonza) at $37^{\circ} \mathrm{C}$ with $5 \% \mathrm{CO}_{2}$. Magnetic labeling was achieved using iron oxide (maghemite) nanoparticles synthetized by coprecipitation of iron salts, and chelated with citric acid. The stability of the colloidal suspension is thus ensured by electrostatic repulsion thanks to the negative charges brought by the citrate carboxylate groups (COO-). The nanoparticles exhibit typical superparamagnetic behavior, with no magnetic hysteresis. Their size distribution can be deduced from the fit of their magnetization curve, well described by a log-normal distribution, with mean value of $8.1 \mathrm{~nm}$, and polydispersity of $35 \%$. Size was also measured by TEM, with an average size of $9.4 \pm 2 \mathrm{~nm}$, slightly superior than the magnetic size. Prior to incubation with cells, nanoparticles were diluted at a final concentration of $[\mathrm{Fe}]=0.2 \mathrm{mM}$ in serum-free RPMI culture medium supplemented with $5 \mathrm{mM}$ free citrate (to avoid precipitation in the culture medium). Cells were then incubated with this solution for $30 \mathrm{~min}$ at $37^{\circ} \mathrm{C}$, then rinsed thoroughly in serumfree RPMI medium and incubated overnight with complete MSCGM medium before further processing.

The iron load per cells was quantified by single cell magnetophoresis. Briefly, detached cells were resuspended at a density of 0.2 million per $\mathrm{ml}$, introduced in a $1 \mathrm{~mm}$ thick chamber, and submitted to a magnetic force created by a permanent magnet (magnetic field $150 \mathrm{mT}$, magnetic field gradient $17 \mathrm{mT} / \mathrm{mm}$ ). The magnetic cell migration towards the magnet is then video-monitored, and the balance of the magnetic force and the viscous drag (provided by the measure of each cell velocity and diameter) leads to the value of each cell magnetic moment, or equivalently mass or iron. More details can be found in [37].

\subsection{Porous scaffold preparation and magnetic cell seeding}

Polysaccharide scaffolds were prepared from a 75:25 mixture of pullulan/dextran plus the cross-linking agent sodium trimetaphosphate (STMP) at $11 \%(\mathrm{w} / \mathrm{v})$ in alkaline conditions (10 $\mathrm{M} \mathrm{NaOH}$ ) [38]. Pores were created with a gas-foaming technique using sodium carbonate in $20 \%$ acetic acid. Scaffolds were freeze-dried for $48 \mathrm{~h}$ to remove water. Rehydration yielded transparent scaffolds with a regular internal lamellar pore structure and a pore size of 185-205 $\mu \mathrm{m}$.

Scaffolds $7 \mathrm{~mm}$ thick with a surface area of $1.8 \mathrm{~cm}^{2}$ were seeded with $2 \times 10^{6}$ magnetic MSC, using either passive diffusion or magnetic condensation. Three to four scaffolds were seeded for each condition and two to four independent experiments were performed. 1) For magnetic condensation, we used a device composed of 9 small magnets ( $3 \mathrm{~mm}$ in diameter, $6 \mathrm{~mm}$ long; 
total surface area $1.8 \mathrm{~cm}^{2}$ ) placed over a permanent neodymium magnet (Fig. 2A). Each magnet created a $150 \mathrm{mT}$ magnetic field and a field gradient of $30 \mathrm{mT} / \mathrm{mm}$ in the vicinity of the scaffold. The scaffold was placed in a glass-bottomed cell culture dish $(35 \mathrm{~mm})$, and the dish was placed on the magnetic device. Magnetically labeled cells were then gently dropped onto the scaffold. 2) For passive seeding experiments, magnetically labeled cells were gently distributed over the entire surface of the scaffold.

All the scaffolds were held at $37^{\circ} \mathrm{C}$ for $5 \mathrm{~min}$ before incubation in differentiation medium. Four negative control scaffolds were seeded for each experiment, two with magnet and two without magnet.

\subsection{Conditions of differentiation}

The seeded scaffolds were first maintained in chondrogenic medium for 4 days in cell culture dishes at $37^{\circ} \mathrm{C}$ to permit cell migration, condensation and adhesion to the scaffold. In case of scaffolds seeded under the magnetic actuation protocol, the magnetic array was left under the scaffold during this 4 days period. The magnets were then removed, and the cellularized scaffolds were left for 21 days either in cell culture dishes (static condition) or in a bioreactor (dynamic condition). The chondrogenic differentiation medium was changed once a week in both conditions.

For dynamic condition, the scaffolds were placed in cages to maintain their integrity, and the assembly was placed in a TisXell bioreactor (QuinXell, Singapore) (Fig. 1), which improves nutrient and gas exchanges by biaxial rotation. This also allowed continuous soft irrigation by laminar flow and mechanical stimulation by transduction. The speeds of arm and chamber rotation can be controlled independently ( 1 to $12 \mathrm{rpm}$ and 1 to $35 \mathrm{rpm}$ respectively). Here, a flow rate of $5 \mathrm{rpm}$ was applied on both the arm and the chamber. This flow rate was recommended by the constructor for soft 3D tissue regeneration. A peristaltic pump was used at $10 \mathrm{rpm}$ to provide a continuous supply of chondrogenic differentiation medium.

\subsection{Chondrogenesis and cell staining}

The chondrogenic differentiation medium was freshly prepared with high-glucose DMEM (Life Technologies, Saint-Aubin, Fance) containing $100 \mathrm{U} / \mathrm{ml}$ penicillin and $100 \mu \mathrm{g} / \mathrm{ml}$ streptomycin, $50 \mu \mathrm{M}$ L-ascorbic acid 2-phosphate, $0.1 \mu \mathrm{M}$ dexamethasone, $1 \mathrm{mM}$ sodium pyruvate, 0.35 mM L-proline (Sigma-Aldrich, Saint-Quentin Fallavier, France), 1\% ITSPremix (Corning, Erembodegem, Belgium) and 10 ng/ml TGF- $\beta 3$ (Interchim, Montluçon, France) [39]. Negative control scaffolds were seeded and matured in culture dishes in the 
same medium lacking TGF- $\beta 3$. After 25 days, half of each scaffold was fixed in $10 \%$ formalin, cryosectioned and stained with toluidine blue $(0.5 \%)$ for 2 min at room temperature (Sigma-Aldrich, Saint-Quentin Fallavier, France) to detect glycosaminoglycans.

\subsection{RNA isolation, $c D N A$ synthesis and quantitative RT-PCR}

Prior extracting total RNA, three to four halves of scaffolds for each experiment were slowly degraded with a mixture of pullulanase/dextranase (40 IU/ml: $60 \mathrm{mg} / \mathrm{ml}$ ) for 15-30 min at $37^{\circ} \mathrm{C}$ (Sigma-Aldrich, Saint-Quentin Fallavier, France). Total RNA was then prepared with a kit from Machery-Nagel (Düren, Germany), including a DNase treatment step to avoid contamination with genomic DNA. Complementary DNA (cDNA) was synthesized with SuperScript II Reverse Transcriptase (Life Technologies, Saint-Aubin, France) from $1 \mu \mathrm{g}$ of total RNA in a final volume of $100 \mu$ l. Quantitative PCR analysis of the chondrogenic genes ACAN, Col2A1, CollA, Col11A1, Col9A1, COMP, RUNX2 and Col10A1 was carried out with the StepOnePlus ${ }^{\mathrm{TM}}$ System and SYBR Green (Life Technologies, Saint-Aubin, Fance) according to the manufacturer's protocol. Levels of chondrogenic gene mRNA were normalized to RPLPO mRNA. The fluorescence cycle threshold $(\mathrm{Ct})$ was used to quantify relative gene expression. Briefly, mRNA levels of the chondrogenic genes were expressed relative to levels of $R P L P O \mathrm{mRNA}\left(\Delta \mathrm{Ct}=\mathrm{Ct}-\mathrm{Ct} \mathrm{t}_{\mathrm{RPP} 0}\right)$, as $2^{-\Delta \Delta \mathrm{Ct}}$, where $\Delta \Delta \mathrm{Ct}=[\Delta \mathrm{Ct}$ of differentiated scaffolds]-[mean $\Delta \mathrm{Ct}$ of negative controls].

Table 1 shows the primer sequences used for quantitative PCR.

\subsection{Statistical analysis}

All measurements are presented as mean values \pm standard error of the mean (SEM). Numbers of independent measurements were systematically superior to $3(n>3)$. To determine significance, one-way ANOVA nonparametric test was performed. A minimum of $99 \%$ confidence level was considered significant: * indicates $\mathrm{p}<0.05$.

\subsection{Transmission electron microscopy (TEM)}

For each condition, two halves of scaffolds were rinsed and fixed with 5\% glutaraldehyde in $0.1 \mathrm{~mol} / \mathrm{L}$ sodium cacodylate buffer, and post-fixed with $1 \%$ osmium tetroxide solution containing $1.5 \%$ potassium cyanoferrate. The cells were then gradually dehydrated in ascending concentrations of ethanol and embedded in Epon resin. Thin sections $(70 \mathrm{~nm})$ were examined with a Zeiss EM 902 transmission electron microscope at $80 \mathrm{kV}$ (MIMA2 platform, INRA, Jouy-en-Josas, France). 
Overlaps of collagen II were measured using the Image $\mathbf{J}$ software by extracting the grey values along the fiber axis, and plotting them as a function of distance.

\subsection{Confocal microscopy}

Magnetically-labeled MSC were fluorescently labeled with pkh26 Red Fluorescent Cell Linker following manufacturer's instructions, and cell nuclei were stained with Hoechst stain solution at 1:1000 (Sigma-Aldrich, Saint-Quentin Fallavier, France). Scaffolds $7 \mathrm{~mm}$ thick were subsequently seeded with $2 \times 10^{6}$ magnetic red/blue MSC using magnetic condensation. Stained cell-scaffold constructs were then observed by confocal microscopy using an Andor Technology spinning disk (Andor Technology, Belfast, Northern Ireland).

\section{Results}

\subsection{Cell seeding in scaffolds}

Mesenchymal stem cells (MSC) were incubated with a magnetic nanoparticle suspension at $[\mathrm{Fe}]=0.2 \mathrm{mM}$. Mean nanoparticle uptake, determined by single-cell magnetophoresis, was equivalent to $5 \pm 0.4 \mathrm{pg}$ iron/cell. We have previously shown that this amount of incorporated nanoparticles does not affect MSC behavior, including osteogenic, adipogenic and chondrogenic differentiation [37].

$7 \mathrm{~mm}$ thick scaffolds with a surface area of $1.8 \mathrm{~cm}^{2}$ were seeded with $2 \times 10^{6}$ magnetically labeled cells. This scaffold thickness was chosen to simulate the thickness of the articular cartilage in the patella, in its central portion, which can be up to 5 or $6 \mathrm{~mm}$ [40]. Besides, after maturation, and implantation, the scaffold thickness is expected to narrow, possibly reaching the normal human knee cartilage thickness, which is $2-3 \mathrm{~mm}$ on the femoral condyles. Scaffold seeding was performed by passive diffusion or by magnetic condensation with the device composed of 9 small magnets (Fig. 2A), placed under the scaffold. The seeded scaffolds were then incubated for 4 days in chondrogenic medium to promote cell migration, condensation and adhesion to the scaffold. On day 4, the cells condensed with magnets were more tightly aggregated (Fig. 2B), and their distribution reflected the pattern of the 9 magnets. Observations of the magnetic-labeled cells stained in red (Fig. 2J, 2M), with nuclei detected in blue (Fig. 2I, 2L), were performed using confocal microscopy to evidence their local organization within the scaffold. Overlaps of 40 images, taken in the thickness of the scaffold, demonstrated that the cells distribution depends strongly on the magnet location. Close to the magnet, cells appear very confined (Fig. 2M, 2L), within pores of the scaffold (Fig. 2K), 
while further from the magnet, only individual cells could be observed (Fig. 2H, 2I, 2J). In contrast, the cells were uniformly distributed after passive seeding (Fig. 2C). On day 25, the cells remained inside the scaffolds in both static conditions (Fig. 2D, E) and dynamic conditions (Fig. 2F, G). The cell aggregates obtained with magnetic confinement were still visible after 25 days of culture (Fig. 2D, F).

\subsection{Efficiency of chondrogenesis within the scaffold}

\subsubsection{Chondrogenic gene expression}

Expression of the chondrogenic genes ACAN (aggrecan), Col2Al (collagen II), Coll1A1 (collagen XI), Col9A1 (collagen IX), and COMP (cartilage oligomeric matrix protein), as well as CollA (collagen I), CollOA1 (collagen X) and RUNX2 (runt-related transcription factor 2), was measured by quantitative PCR after 25 days of chondrogenesis. The negative control consisted of scaffolds seeded with the same number of cells and cultured in dishes without TGF- $\beta 3$. Gene expression was performed on negative control scaffolds for each experiment, and no difference was detected between those seeded magnetically or passively. So, the obtained values in both conditions $(\sim 1 \pm$ SEM), have been pooled to enhance the number of negative controls for each experiment. Cells were retrieved by enzymatic degradation of the scaffolds before extraction of total RNA. Quantitative PCR showed an increase in ACAN, Col II and Col XI expressions, significant for both Col II and Col XI, after magnetic seeding and compared to the values without magnetic seeding (Fig. 3A). The increase was also significantly higher after dynamic maturation than after static maturation for Col II and XI, and for the three genes, the highest expression was obtained when magnetic seeding was combined with dynamic condition (Fig. 3A). It must be noted that these three gene expressions were all significantly much higher than the expressions of the negative controls $(1.1 \pm 0.15 ; 1.08 \pm 0.12$ and $1.01 \pm 0.06$ for $A G C$, Col II and XI respectively). COMP and Col IX expression did not differ according to the seeding or differentiation conditions, except for significant lower Col IX expression after static condition (Fig. 3A). However, these two genes were far more weakly expressed than ACAN, Col II and Col XI (respectively 12 and 28-30fold the negative control value). Col I and $\mathrm{Col} X$ expressions were calculated as a percentage of mean Col II expression. Both these genes were far more weakly expressed than Col II, especially when magnetic seeding was combined with dynamic maturation (Fig. 3B). Col I expression remained very low ( $0.32 \%$ of $\mathrm{Col}$ II expression), even in the least favorable chondrogenic conditions (passive seeding and static condition), and significantly different 
compared to $0.016 \%$ in optimal conditions (magnetic seeding with dynamic condition). By contrast, $\mathrm{Col} X$ expression reached $5.4 \%$ of $\mathrm{Col}$ II expression in these optimal conditions and $444 \%$ in the least favorable conditions. RUNX2 expression did not differ from the negative control value $(1.07 \pm 0.11)$ after static maturation $(1.25 \pm 0.17$ and $1.27 \pm 0.16$ without and with magnet respectively), and only reached respectively 2.7 -fold \pm 0.9 and 4.2 -fold \pm 2.3 after passive and magnetic seeding with bioreactor maturation (data not shown).

\subsubsection{Histological analysis}

Cryosections $12 \mu \mathrm{m}$ thick were prepared through the entire thickness of scaffolds, and sections from the center and edges were stained with toluidine blue. For these histological analyses, only magnetically seeded scaffolds were used to compare static and dynamic maturation. The polysaccharide composition of the scaffold was observed with the blue staining of its porous structure. By contrast, GAG deposition was evidenced throughout the thickness of the scaffold due to the metachromatic blue-purple color. GAG content was significantly higher when the scaffolds were matured dynamically (Fig. 4B) rather than statically (Fig. 4A). Moreover, differentiated cellular aggregates were more compact and had a less abundant extracellular matrix in the static conditions. Higher magnifications of scaffolds produced after magnetic seeding and bioreactor maturation revealed the synthesis of a GAG-rich extracellular matrix (Fig. 5). Fibers were also observed within the extracellular matrix, possibly corresponding to a collagen II network.

\subsubsection{Transmission electron microscopy}

In order to better identify the structure of the synthesized matrix, scaffolds were processed for electron microscopy. We first examined large views of semi-thin scaffold sections $(500 \mathrm{~nm}$ to $1 \mu \mathrm{m})$. When differentiation took place in the bioreactor, the extracellular matrix was more developed and abundant (Fig. 6A) than after static condition (Fig. 6B). In addition, the differentiated cells were larger and the extracellular matrix was less compact after dynamic condition. Observation of thin sections $(70 \mathrm{~nm})$ showed that the differentiated cells had synthesized a large amount of long collagen fibers after bioreactor maturation (Fig.7A). The characteristic periodicity of collagen II, was also visible (Fig. 7B). Collagen fibers were smaller and less abundant in static conditions (Fig. 7C), and undetectable in negative controls (Fig. 7D). In addition, we observed signs of an intense protein synthesis, with an abundant granular endoplasmic reticulum as well as intracellular neosynthesized collagen fibers (Fig. $8)$. 


\section{Discussion}

Despite intensive efforts, it has so far proved impossible to obtain a homogeneous and durable replacement cartilage. Several issues arise when using autologous chondrocytes, including difficulties in maintaining the chondrocyte phenotype and inefficient extracellular matrix turnover [11].

One way of overcoming the loss of the chondrocyte phenotype is to start with mesenchymal stem cells (MSC) and induce them to differentiate into chondrocytes. A critical step for chondrocyte differentiation of MSC is cell compaction, which may be achieved by centrifugation or alternatively by magnetic condensation. However, poor nutrient diffusion and subsequent necrosis at the center of aggregates may limit the size of the obtained tissue. The use of scaffolds represents a valuable alternative to provide suitable environments for MSC seeding and facilitate implantation in patients. Nevertheless, despite the development of several different types of 3D structure, it has proved difficult or impossible to differentiate MSC into functional chondrocytes within a scaffold. This may be due to several factors, mainly the lack of cell condensation into scaffold impeding the chondrogenic process and the large number of cells needed to populate structures larger than a millimeter. In addition, the scaffold should be completely bioresorbable and biocompatible; the pores must be large enough for the cells to diffuse; and the cells must be able to remain into the scaffold, especially when dynamic condition is used.

Here we report the first successful MSC chondrogenesis within the core of a scaffold. The key factors in this success were the combination of i) magnetic condensation of MSC within the scaffold, ii) dynamic condition in a bioreactor and, above all, iii) the use of a flexible porous polysaccharide matrix enabling cell penetration throughout the structure. We were thus able to seed a large number of cells compatible with the surface area and thickness of the scaffold. Finally, to avoid necrosis and provide mechanical stimulation, we used dynamic culture conditions to ensure continuous nutrient and gas diffusion.

The precise architecture of the scaffold is crucial for cells to diffuse and adhere, and also to induce and maintain chondrogenic differentiation. The matrix mesh influences intracellular signaling pathways, thereby modifying gene expression and cellular fate. Here, we promoted magnetic cell condensation within the naturally derived pullulan/dextran scaffold. Pullulan 
has been previously used to enhance MSC adhesion and persistence at the articular cartilage surface [41]. Importantly, the pore size must be compatible with cell condensation and further

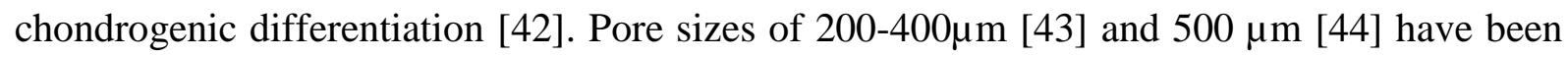
reported to enhance osteogenic differentiation. We used a pore size of 185-205 $\mu \mathrm{m}$. The compliance of the pullulan/dextran scaffold, combined with a pore size suitable for nutrient and gas exchanges as well as mechanic stimulation (by transduction), enhanced chondrogenesis. Another important issue is the appropriate number of cells. High seeding densities in polymer matrices have been reported to promote the formation of a cartilaginous matrix [45]. We found that a lower number of cells $\left(1.5 \times 10^{6}\right.$ instead of $2 \times 10^{6}$ cells $)$ gave poorer results in terms of chondrogenesis, despite magnetic condensation (data not shown). Finally, pullulan based scaffolds with an appropriate structure and elasticity constitute a 3D micro-environment that have been shown to be bioresorbable in several animal models [46, 47].

Iron oxide nanoparticle labeling is a precondition for magnetic condensation. We have previously shown that MSC labeling with iron oxide nanoparticles has no negative impact on chondrogenic differentiation at concentrations lower than $10 \mathrm{pg}_{\mathrm{Fe}} / \mathrm{cell}$ [37]. Here, a value of $5 \pm 0.4 \mathrm{pg}_{\mathrm{Fe}} /$ cell was measured by magnetophoresis. It is noteworthy that iron oxide nanoparticles are already used in clinics as contrast agents for magnetic resonance imaging (MRI) and are being envisaged as labels to track the fate of cell grafts in vivo. Importantly, magnetic labeling of MSC should allow replacement cartilage to be monitored by MRI for several weeks after grafting [48]. Finally, magnetic seeding has already been used to enhance cell incorporation by scaffolds [28, 51], and magnetically labeled cells have also been constrained into three-dimensional constructs by the application of an external magnetic force to improve chondrogenesis [16]. Here, magnetic forces were used both to enhance cell seeding in scaffold and to induce cell condensation favorable to chondrogenic differentiation. The main components of native cartilage are aggrecan and collagen type II. It has been suggested that excessively rapid initial GAG synthesis impedes collagen II synthesis [11]. Here, both aggrecan and collagen II were abundantly synthesized, especially collagen II. These results are consistent with the higher mRNA expression of Col II than of ACAN in normal human cartilage [52]. Aggrecans are vast assemblies of proteoglycans that are connected to the collagenous network via non covalent bonds. GAG chains are highly hydrophilic and polyanionic, generating high osmotic pressure that gives cartilage its softness [53]. Collagen II represents more than $90 \%$ of total collagen in cartilage. Other collagens, the exact functions of which are not well established, appear to structure the extracellular matrix: 
type XI associates closely with type II to form a 3D fibrous network, while type IX is covalently linked to the surface of type II. Here, both two types of collagen were synthesized by chondrocytes, and collagen type XI synthesis increased simultaneously with collagen type II synthesis. By contrast, collagen type IX synthesis did not seem to depend on the conditions of chondrogenesis.

Col II provides tensile strength to cartilage thanks to its characteristic structure, in which each of the three polypeptide chains forms a repeated motif with a pitch of 18 amino acids. The three chains are supercoiled with a gap of one residue, leading to a periodicity of 0.8 Angströms $[54,55]$. Here, overlaps of neo-synthesized collagen II was clearly seen on TEM images (between 10 and 20nm). Thus, not only is collagen II synthesized in large amounts, but collagen fibrils are supercoiled around a central axis with characteristic periodicity. Cartilage oligomeric matrix protein $(C O M P)$ appears to be involved in collagen fibril assembly [56]. This protein is a biological marker of cartilage degradation in serum and synovial fluid [57], and its level decreases during effective treatment of arthritis [58]. Here, we found that chondrocytes expressed COMP regardless of the differentiation conditions. RUNX2 is a key transcription factor involved in bone formation and in the early stages of chondrocyte condensation. It is degraded when chondrogenesis is initiated, and blocks chondrogenesis during osteogenic differentiation [59]. We found that RUNX2 gene expression was negligible at the end of the chondrogenetic process. Collagen type I is not typically found in articular cartilage. However, MSC express this collagen and could generate fibrous cartilage as well [11]. Here, collagen type I expression was negligible, representing only $0.016 \%$ of Col II expression in optimal conditions of chondrogenesis. Collagen $\mathrm{X}$ is associated with arthrosis and has been proposed as a marker of late-stage chondrocyte hypertrophy [60]. Here, collagen X expression remained high (5.4\% of Col II), even in optimal conditions. To prevent this, the maturing process could be carried out in hypoxia. Still, it must be noted that hypoxia was found inconclusive in a study using chondrocytes [61]. Besides, it is not known whether the oxygen tension remains at $21 \%$ (normoxia) at the center of a scaffold $7 \mathrm{~mm}$ thick. However, a positive impact of hypoxia has also been reported, leading to down-regulation of $\mathrm{Col} \mathrm{X}$, and up-regulation of Col II and aggrecan expression, for MSC pellets [62, 63], or with $2 \mathrm{~mm}$-thickness hyaluronic acid porous scaffold seeded with bovine MSC [64]. In another study, preconditioning for one week in normoxic conditions before initiating chondrogenesis in hypoxic conditions has given the best results [65]. Differentiation under an oxygen tension of $2 \%$ has been reported to reduce the expression of $\operatorname{Col} X$ and $R U N X 2$ concomitantly, leading to reduced endochondral ossification 
during the first two weeks [66]. Rampersad et al. [67] showed that Col X expression at the cell surface could be suppressed by using a nitrogen-rich plasma-polymerized thin film. In addition to oxygen, the role of the maturation period needs to be established, along with transient delivery of exogenous TGF- $\beta 3$ [68].

Finally, it is well established that a suitable mechanical environment is essential for successful chondrogenesis. It has previously been shown that the rate and extent of Col II and aggrecan expression by differentiating chondrocytes is significantly enhanced by compressive forces [69], and also with chondrocytes on agarose disks [70]. The composition and mechanical properties of engineered cartilage with a polyglycolic acid scaffold can be modulated by flow conditions during bovine chondrocyte culture [71]. Other studies have highlighted the role of a mechanical stimulation in initiating stem cells chondrogenic differentiation in various bioreactor systems applying different stimuli (transduction, compression, combined compression/shear) [72-76]. Thus, a bioreactor seems essential for engineering cellularized scaffolds, as it offers a dynamic mechanical environment that generates appropriate physiological stimuli and enhances chondrogenesis [77]. Moreover, a bioreactor ensures nutrient diffusion and waste elimination [78]. Here, we used the TisXell bioreactor, which generates fluid shear stress to promote mechanical stimulation by transduction and slight shear stress. An external peristaltic pump continuously injected the scaffold with differentiation medium. The combined use of magnetic condensation and bioreactor incubation strongly enhanced chondrogenesis in 3D scaffolds.

In conclusion, we successfully prepared neo-cartilage by using stem cells magnetically condensed into a porous scaffold. The scaffolds thus obtained are of a size $\left(1.8 \mathrm{~cm}^{2}, 7 \mathrm{~mm}\right.$ thick) suitable for replacing damaged cartilage. To date, in spite of significant recent advances, cartilage tissue engineering still misses the production of an engineered cartilage matching closely the properties of the native one. The 3D cell-scaffold construct proposed here, derived from magnetic stem cells seeding combined with a dynamic environment, thus seems to be a promising strategy for regenerative medicine applications.

\section{Acknowledgments}

We thank QuinXell Technologies and CellD for providing us with the TisXell bioreactor. We particularly thank Lothar Grannemann, Dominique Ghozlan, and Hicham Kacimi for their help. Christine Péchoux and Sophie Chat are thanked for electron microscopy. David Pereira is as well thanked for his help with confocal microscopy. This work was supported by ANR 
(Agence Nationale de la Recherche) within the framework of the MagStem project (ANR-11 SVSE5).
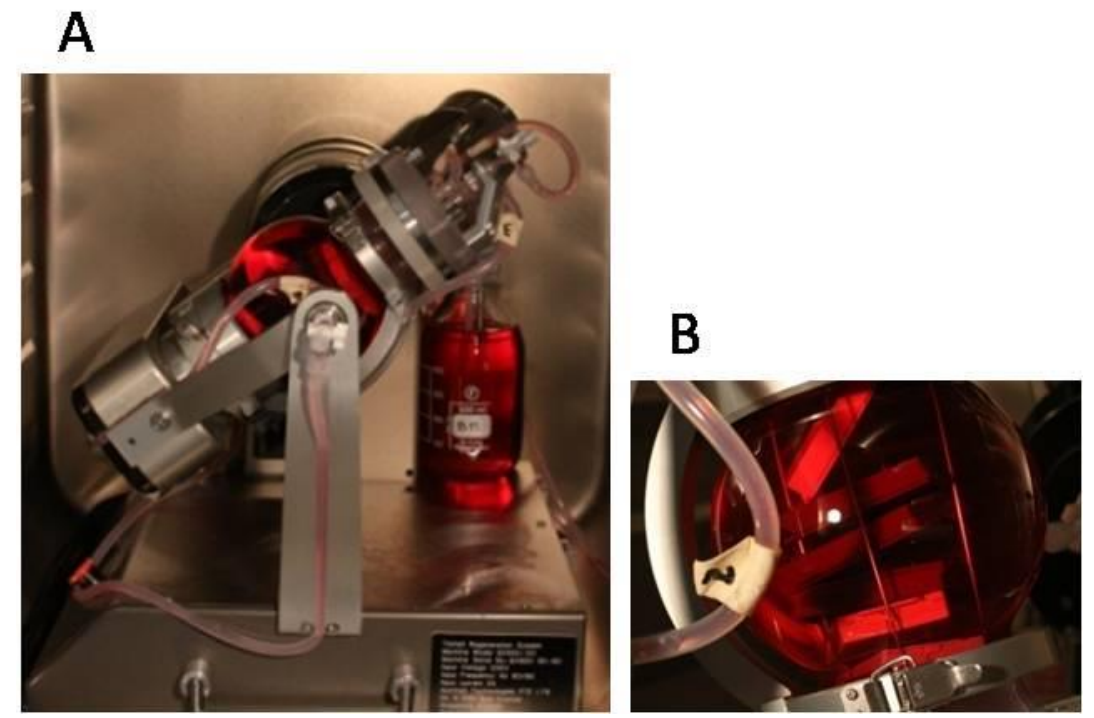

Fig. 1. The TisXell cellular bioreactor (A) applies biaxial rotation, providing continuous irrigation of the 3D scaffold and improving gas exchanges. The arm and chamber rotational speeds can be controlled independently ( 1 to $12 \mathrm{rpm}$ and 1 to $35 \mathrm{rpm}$ respectively). A flow rate of $5 \mathrm{rpm}$ was applied to both the arm and the chamber, as recommended by the constructor for soft 3D tissue regeneration. A peristaltic pump provides a continuous supply of culture medium at $10 \mathrm{rpm}$. The scaffolds were placed within cages to prevent disruption, and the assemblies were placed in the $500 \mathrm{ml}$ chamber (B) containing differentiation medium. 


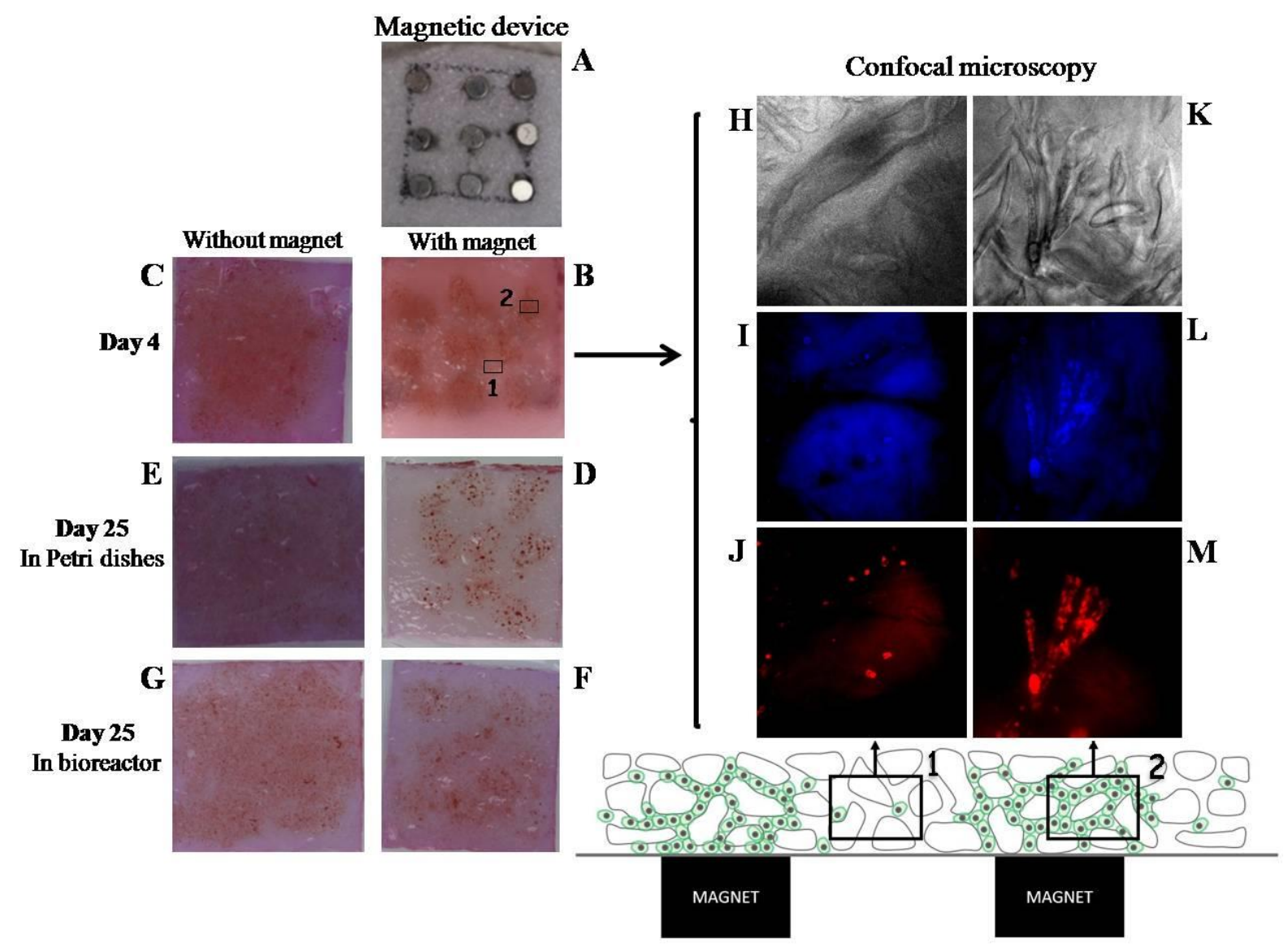

Fig. 2. Magnetic MSC in 7-mm-thick scaffolds, with or without magnetic condensation using a device composed of 9 small magnets (A). Magnetic cells were clearly visible in the form of aggregates on day 4 after seeding of $2 \times 10^{6}$ cells with (B) or without (C) magnetic forces. At day 4, confocal observation of the magnetic-labeled MSC compaction by magnetic attraction into scaffold was performed, after cell membrane staining with the red fluorescent pkh26 (J, $\mathrm{M})$, and cell nuclei staining with the Hoechst stain solution (I, L): cells were more confined into scaffold when closer to the magnet reported to the inset $2(\mathrm{~K}, \mathrm{~L}, \mathrm{M})$, compared to those further from the magnet reported to the inset $1(\mathrm{H}, \mathrm{I}, \mathrm{J})$ (magnification 10x). The confocal pictures showed the overlap of 40 images, and red and blue staining were superposed in inset $1(\mathrm{~J}, \mathrm{I})$ and $2(\mathrm{M}, \mathrm{L})$. Images $\mathrm{H}$ and $\mathrm{K}$ represented a slide of scaffold. The scaffolds were then matured for 21 days in static conditions (Petri dishes) (D, E) or dynamic conditions (TisXell bioreactor) $(\mathrm{F}, \mathrm{G})$. On day 25 of chondrogenesis, the cells remained inside the scaffolds in both static (D, E) and dynamic conditions (F, G). The aggregates formed by the magnetic device during the first 4 days were still visible on day $25(\mathrm{D}, \mathrm{F})$. 

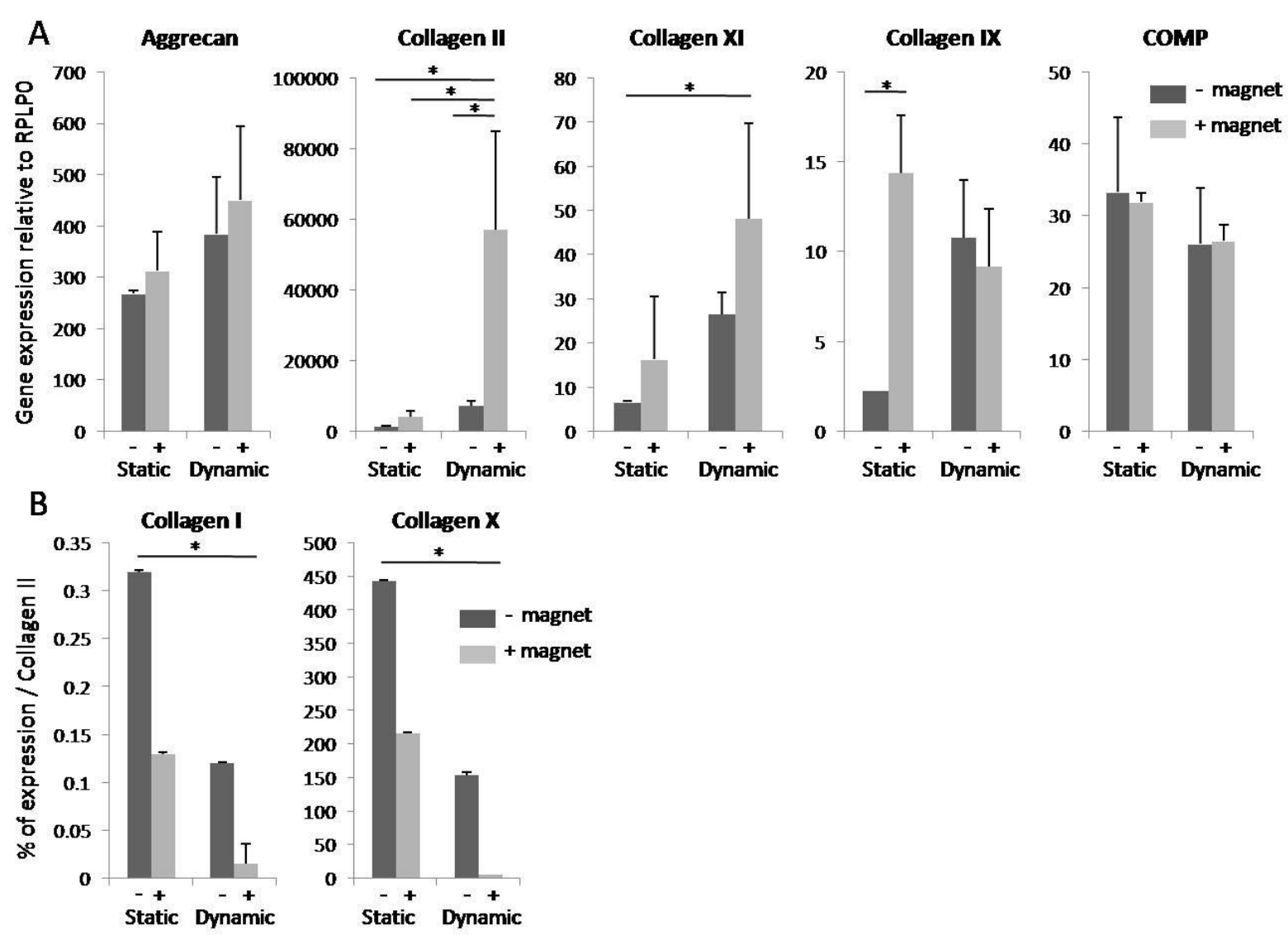

Fig. 3. Gene expression on day 25 of static or dynamic condition, with or without magnetic seeding, as measured by quantitative PCR. Aggrecan, Col II, XI and IX and COMP expression (A) was normalized to RPLPO mRNA and expressed in arbitrary units relative to controls $(\sim 1$ \pm SEM) seeded and matured without TGF- $\beta 3$. Col I and $X$ expression (B) was evaluated in the same conditions and expressed as a percentage of $\mathrm{Col} \mathrm{II} \mathrm{expression.} \mathrm{Results} \mathrm{are} \mathrm{presented} \mathrm{as}$ means \pm SEM of two to four independent experiments. Expression of the specific cartilage matrix genes aggrecan, Col II and XI was clearly increased by combining magnetic seeding with dynamic condition. * denotes a statistical difference using the One-way ANOVA nonparametric test ( $\mathrm{p}$-value $<0.05)$. 

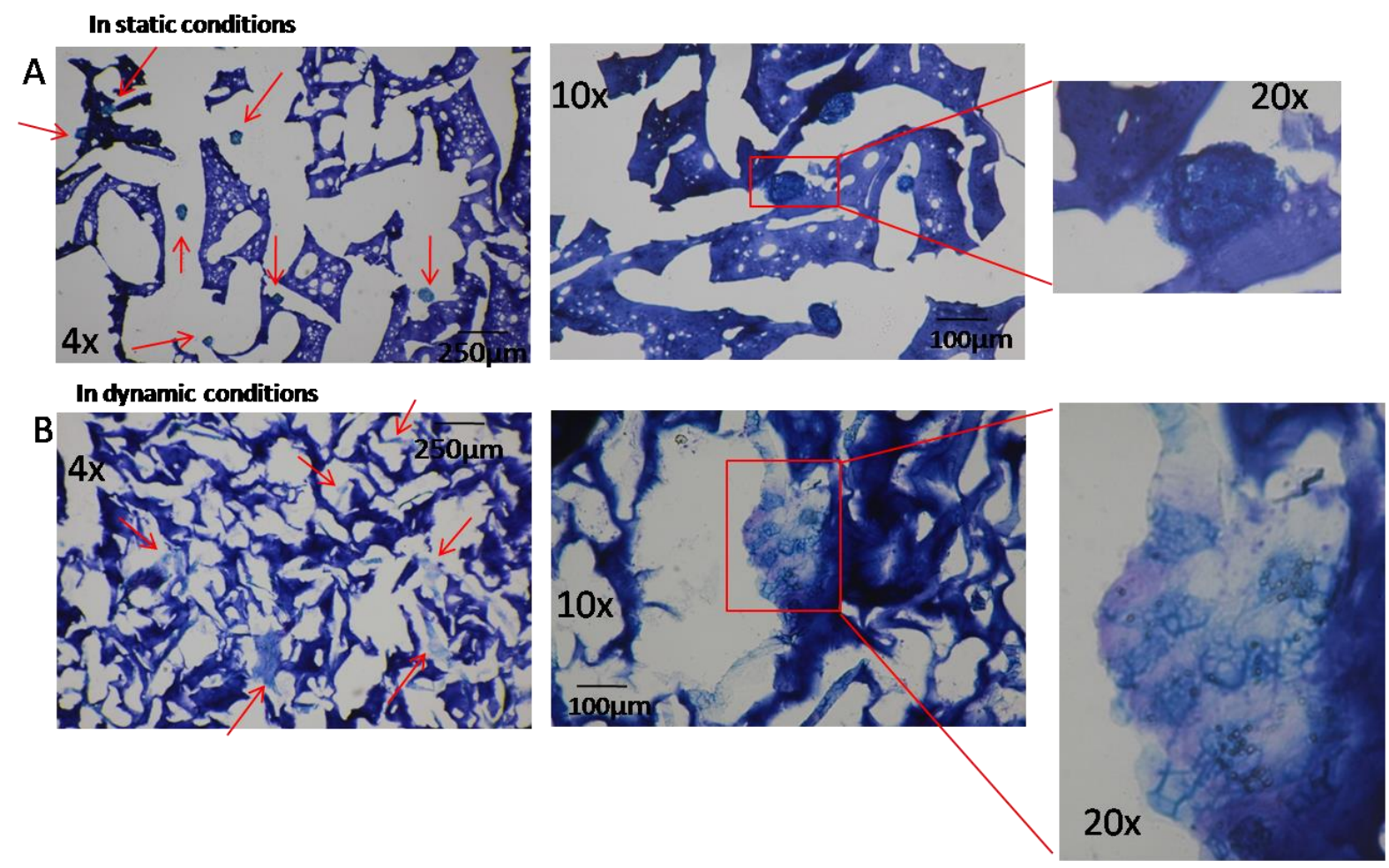

Fig. 4. Sections $12 \mu \mathrm{m}$ thick prepared from the center of the scaffold were stained with toluidine blue after 25 days of chondrogenesis in static (A) or dynamic conditions (B), both with magnetic seeding. Glycosaminoglycan (GAG) deposits are evidenced by blue-pruple coloration. GAG content was clearly higher after dynamic condition. Red arrows indicate aggregates of differentiated cells.

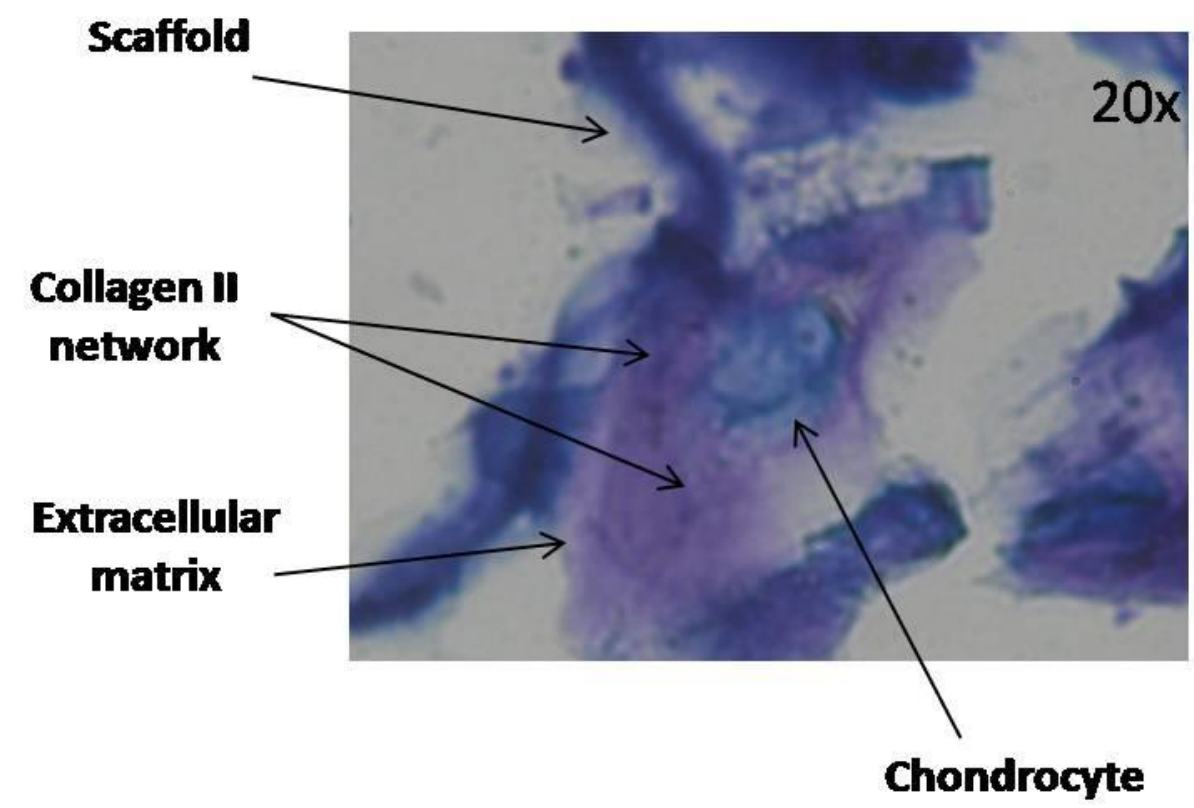


Figure 5. Higher magnification on neosynthesized chondrocytes. After magnetic seeding and dynamic maturation, toluidine blue staining of scaffold sections showed that chondrocytes had synthesized a rich extracellular matrix.

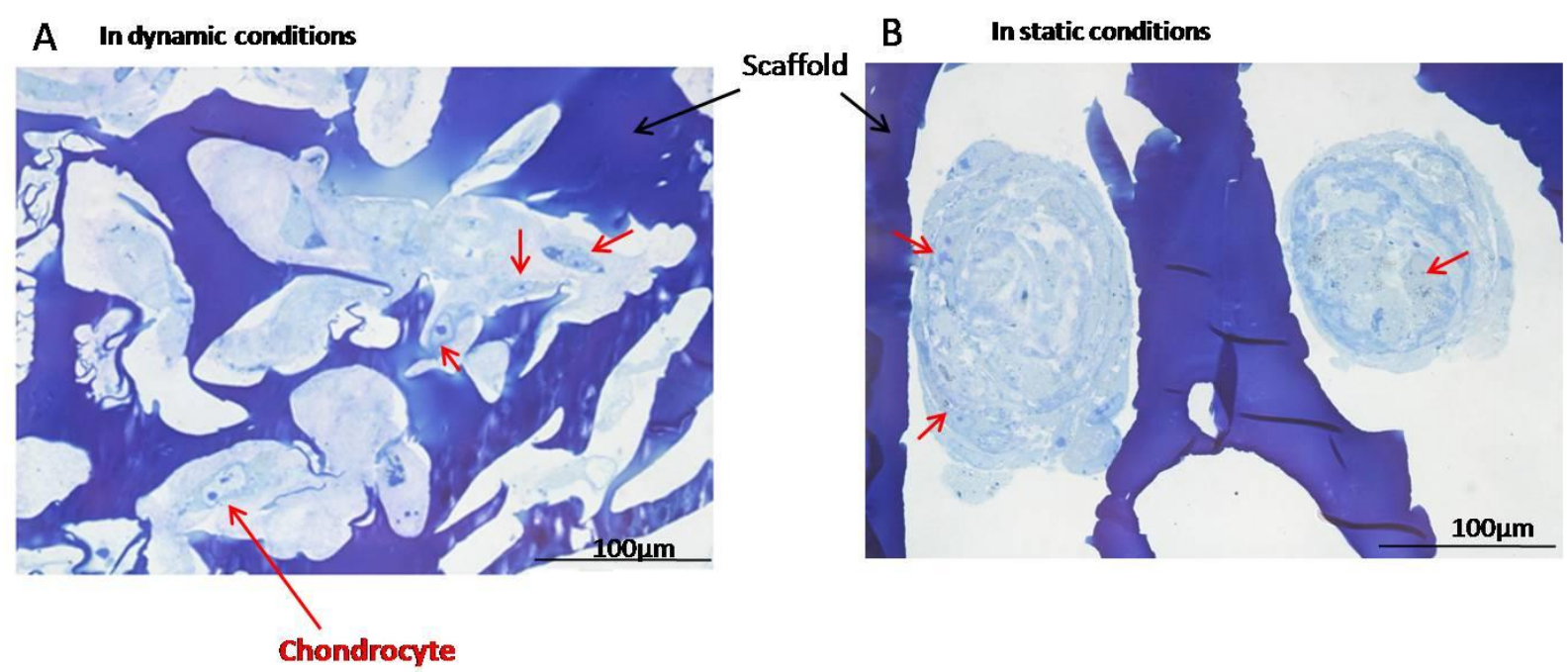

Fig. 6. Semi-thin scaffold sections (500 $\mathrm{nm}$ to $1 \mu \mathrm{m})$ after 25 days of chondrogenesis in dynamic (A) or static (B) conditions both with magnetic seeding. The extracellular matrix was more abundant after dynamic condition than after static condition.

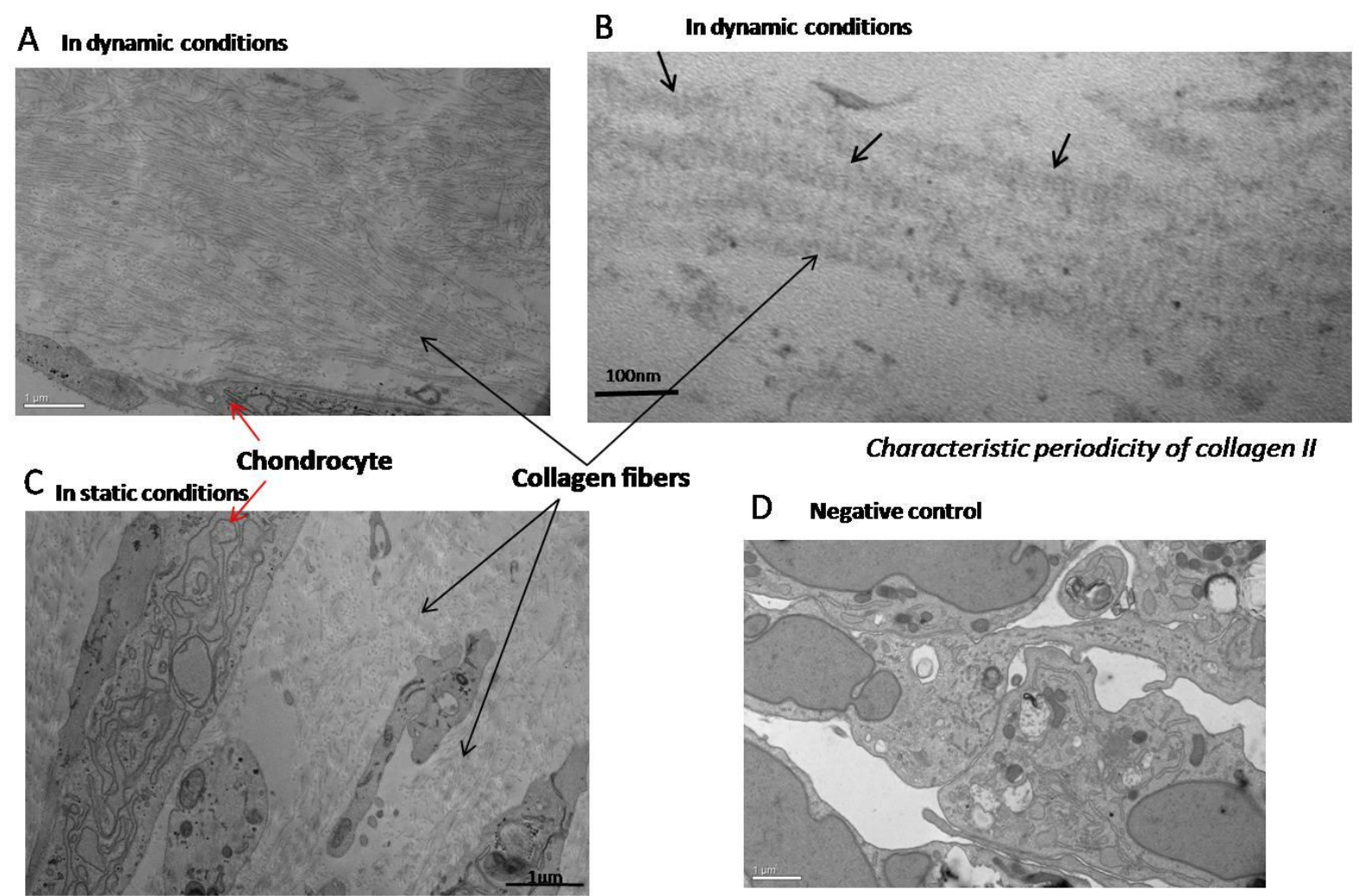


Fig. 7. Transmission electron microscopy of thin scaffold sections $(70 \mathrm{~nm})$. Neosynthesized chondrocytes (red arrow) synthesized large amounts of collagen fibers when chondrogenesis took place in dynamic conditions (A) (scale bar $=1 \mu \mathrm{m}$ ). These long collagen fibers presented the characteristic periodicity of collagen II (black arrows, B) (scale bar $=100 \mathrm{~nm}$ ). Fewer, smaller collagen fibers were observed when chondrogenesis took place in static conditions (C) $($ scale bar $=1 \mu \mathrm{m})$, and no collagen fibers were observed in negative controls, which was matured in static conditions without TGF- $\beta 3$ (D) (scale bar $=1 \mu \mathrm{m})$. (A, C) x3000, (B) x30 000, (D) x2500.

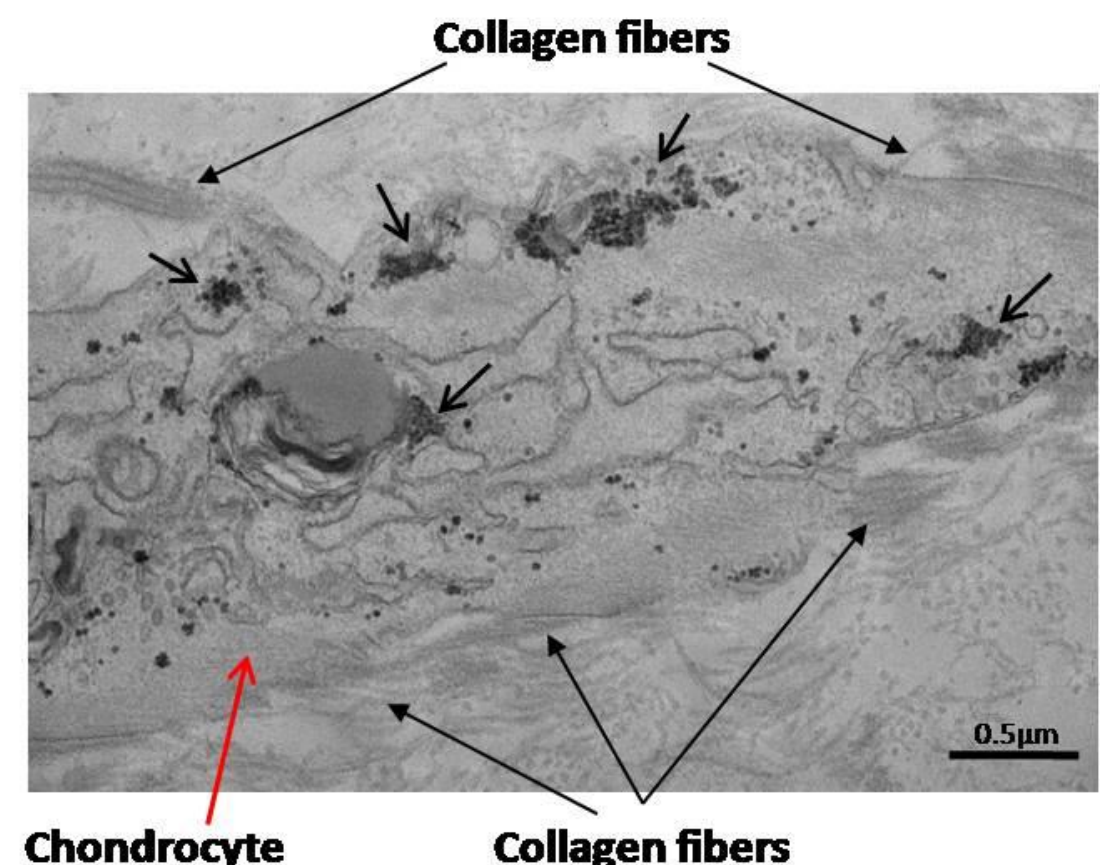

Fig. 8. The abundant granular endoplasmic reticulum (small black arrows) inside a neosynthesized chondrocyte in dynamic conditions (red arrow), and secretion of neosynthesized collagen fibers (large black arrows) indicated an intense protein synthesis. x6000 (scale bar $=0.5 \mu \mathrm{m})$. 
Table 1

Primer sequences used for quantitative PCR

\begin{tabular}{llc}
\hline Name & Sequence & Gene bank \\
\hline Aggrecan & 5'-TCTACCGCTGCGAGGTGAT-3' & NM_001135.3 \\
(ACAN) & 3'-TGTAATGGAACACGATGCCTTT-5' & \\
Collagen I & 5'-TGCCCACAGGCATAAAAGG-3' & NM_000089.3 \\
(COL1A1) & 3'-TTTATGGTGTAGGGAATGAAGAACTG-3' & \\
Collagen II & 5'-ACTGGATTGACCCCAACCAA-3' & NM_001844.4 \\
(COL2A1) & 3'-TCCATGTTGCAGAAAACCTTCA-5' & \\
Collagen XI & 5'-GAAGTGGCATCGGGTAGCA-3' & NM_080629-2 \\
(COL11A1) & 3'-CTATCAAGTGGTTTCGTGGTTTTCT-5' & \\
COMP & 5'-GCCTGGCTGTGGGTTACACT-3' & NM_000095-2 \\
(COMP) & 3'-CGTGACCGTGTTCACATGGA-5' & \\
RUNX2 & 5'-CGAATGGCAGCACGCTATTA-3' & NM_001024630.3 \\
(RUNX2) & 3'-TGGCTTCCATCAGCGTCAA-5' & \\
Collagen X & 5'-TGCCCACAGGCATAAAAGG-3' & NM_000493.3 \\
(Col10A1) & 3'-TTTATGGTGTAGGGAATGAAGAACTG-3' & \\
\hline
\end{tabular}

\section{References}

[1] E. Losina, A.M. Weinstein, W.M. Reichmann, S.A. Burbine, D.H. Solomon, M.E. Daigle, B.N. Rome, S.P. Chen, D.J. Hunter, L.G. Suter, J.M. Jordan, J.N. Katz, Lifetime risk and age at diagnosis of symptomatic knee osteoarthritis in the US, Arthritis Care Res (Hoboken). 65 (2013) 703-11.

[2] R.C. Lawrence, D.T. Felson, C.G. Helmick, L.M. Arnold, H. Choi, R.A. Deyo, S. Gabriel, R. Hirsch, M.C. Hochberg, G.G. Hunder, J.M. Jordan, J.N. Katz, H.M. Kremers, F. Wolfe, Estimates of the prevalence of arthritis and other rheumatic conditions in the United States. Part II, Arthritis Rheum. 58 (2008) 26-35.

[3] M.D. Dibonaventura, S. Gupta, M. McDonald, A. Sadosky, D. Pettitt, S. Silverman, Impact of self-rated osteoarthritis severity in an employed population: cross-sectional analysis of data from the national health and wellness survey, Health Qual Life Outcomes. 10 (2012) 30 .

[4] S.R. Kingsbury, H.J. Gross, G. Isherwood, P.G. Conaghan, Osteoarthritis in Europe: impact on health status, work productivity and use of pharmacotherapies in five European countries, Rheumatology (Oxford). 53 (2014) 937-47.

[5] C. Le Pen, Les conséquences socioéconomiques de l'arthrose en France. Etude COART France, Revue du rhumatisme. 72 (2005) 1326-1330.

[6] T. Aigner, L. McKenna, Molecular pathology and pathobiology of osteoarthritic cartilage, Cell Mol Life Sci. 59 (2002) 5-18. 
[7] M. Brittberg, A. Lindahl, A. Nilsson, C. Ohlsson, O. Isaksson, L. Peterson, Treatment of deep cartilage defects in the knee with autologous chondrocyte transplantation, N Engl J Med. 331 (1994) 889-95.

[8] W. Bartlett, C.R. Gooding, R.W. Carrington, J.A. Skinner, T.W. Briggs, G. Bentley, Autologous chondrocyte implantation at the knee using a bilayer collagen membrane with bone graft. A preliminary report, J Bone Joint Surg Br. 87 (2005) 330-2.

[9] W. Bartlett, J.A. Skinner, C.R. Gooding, R.W. Carrington, A.M. Flanagan, T.W. Briggs, G. Bentley, Autologous chondrocyte implantation versus matrix-induced autologous chondrocyte implantation for osteochondral defects of the knee: a prospective, randomised study, J Bone Joint Surg Br. 87 (2005) 640-5.

[10] L. Batty, S. Dance, S. Bajaj, B.J. Cole, Autologous chondrocyte implantation: an overview of technique and outcomes, ANZ J Surg. 81 (2011) 18-25.

[11] L. Kock, C.C. van Donkelaar, K. Ito, Tissue engineering of functional articular cartilage: the current status, Cell Tissue Res. 347 (2012) 613-27.

[12] L. Song, D. Baksh, R.S. Tuan, Mesenchymal stem cell-based cartilage tissue engineering: cells, scaffold and biology, Cytotherapy. 6 (2004) 596-601.

[13] S. Boeuf, W. Richter, Chondrogenesis of mesenchymal stem cells: role of tissue source and inducing factors, Stem Cell Res Ther. 1 (2010) 31.

[14] S. Meirelles Lda, A.M. Fontes, D.T. Covas, A.I. Caplan, Mechanisms involved in the therapeutic properties of mesenchymal stem cells, Cytokine Growth Factor Rev. 20 (2009) 419-27.

[15] B.S. Schon, K. Schrobback, M. van der Ven, S. Stroebel, G.J. Hooper, T.B. Woodfield, Validation of a high-throughput microtissue fabrication process for 3D assembly of tissue engineered cartilage constructs, Cell Tissue Res. (2012).

[16] D. Fayol, G. Frasca, C. Le Visage, F. Gazeau, N. Luciani, C. Wilhelm, Use of magnetic forces to promote stem cell aggregation during differentiation, and cartilage tissue modeling, Adv Mater. 25 (2013) 2611-6.

[17] S. Bhumiratana, R.E. Eton, S.R. Oungoulian, L.Q. Wan, G.A. Ateshian, G. VunjakNovakovic, Large, stratified, and mechanically functional human cartilage grown in vitro by mesenchymal condensation, Proc Natl Acad Sci U S A. 111 (2014) 6940-5.

[18] M. Sato, M. Yamato, K. Hamahashi, T. Okano, J. Mochida, Articular cartilage regeneration using cell sheet technology, Anat Rec (Hoboken). 297 (2014) 36-43.

[19] Y.J. Chuah, Y. Zhang, Y. Wu, N.V. Menon, G.H. Goh, A.C. Lee, V. Chan, Y. Kang, Combinatorial effect of substratum properties on mesenchymal stem cell sheet engineering and subsequent multi-lineage differentiation, Acta Biomater. 23 (2015) 52-62.

[20] S. Ansboro, J.S. Hayes, V. Barron, S. Browne, L. Howard, U. Greiser, P. Lalor, F. Shannon, F.P. Barry, A. Pandit, J.M. Murphy, A chondromimetic microsphere for in situ spatially controlled chondrogenic differentiation of human mesenchymal stem cells, J Control Release. 179 (2014) 42-51.

[21] G.A. Whitney, K. Jayaraman, J.E. Dennis, J.M. Mansour, Scaffold-free cartilage subjected to frictional shear stress demonstrates damage by cracking and surface peeling, $\mathrm{J}$ Tissue Eng Regen Med. (2014).

[22] D. Puppi, F. Chiellini, A.M. Piras, E. Chiellini, Polymeric materials for bone and cartilage repair, Progress in Polymer Science. 35 (2010) 403-440.

[23] N. Bhardwaj, D. Devi, B.B. Mandal, Tissue-engineered cartilage: the crossroads of biomaterials, cells and stimulating factors, Macromol Biosci. 15 (2015) 153-82.

[24] D.W. Hutmacher, Scaffolds in tissue engineering bone and cartilage, Biomaterials. 21 (2000) 2529-43. 
[25] W. Tan, J. Twomey, D. Guo, K. Madhavan, M. Li, Evaluation of nanostructural, mechanical, and biological properties of collagen-nanotube composites, IEEE Trans Nanobioscience. 9 (2010) 111-20.

[26] B.A. Harley, A.K. Lynn, Z. Wissner-Gross, W. Bonfield, I.V. Yannas, L.J. Gibson, Design of a multiphase osteochondral scaffold III: Fabrication of layered scaffolds with continuous interfaces, J Biomed Mater Res A. 92 (2010) 1078-93.

[27] S.R. Caliari, B.A. Harley, Collagen-GAG scaffold biophysical properties bias MSC lineage choice in the presence of mixed soluble signals, Tissue Eng Part A. 20 (2014) 246372.

[28] K. Shimizu, A. Ito, H. Honda, Enhanced cell-seeding into 3D porous scaffolds by use of magnetite nanoparticles, J Biomed Mater Res B Appl Biomater. 77 (2006) 265-72.

[29] R. Sensenig, Y. Sapir, C. MacDonald, S. Cohen, B. Polyak, Magnetic nanoparticle-based approaches to locally target therapy and enhance tissue regeneration in vivo, Nanomedicine (Lond). 7 (2012) 1425-42.

[30] Amrita, A. Arora, P. Sharma, D.S. Katti, Pullulan-based composite scaffolds for bone tissue engineering: Improved osteoconductivity by pore wall mineralization, Carbohydr Polym. 123 (2015) 180-9.

[31] X. Jiang, M.H. Nai, C.T. Lim, C. Le Visage, J.K. Chan, S.Y. Chew, Polysaccharide nanofibers with variable compliance for directing cell fate, J Biomed Mater Res A. 103 (2015) 959-68.

[32] M.F. Cutiongco, M.H. Tan, M.Y. Ng, C. Le Visage, E.K. Yim, Composite pullulandextran polysaccharide scaffold with interfacial polyelectrolyte complexation fibers: a platform with enhanced cell interaction and spatial distribution, Acta Biomater. 10 (2014) 4410-8.

[33] V.W. Wong, K.C. Rustad, M.G. Galvez, E. Neofytou, J.P. Glotzbach, M. Januszyk, M.R. Major, M. Sorkin, M.T. Longaker, J. Rajadas, G.C. Gurtner, Engineered pullulan-collagen composite dermal hydrogels improve early cutaneous wound healing, Tissue Eng Part A. 17 (2011) 631-44.

[34] A. Autissier, C. Le Visage, C. Pouzet, F. Chaubet, D. Letourneur, Fabrication of porous polysaccharide-based scaffolds using a combined freeze-drying/cross-linking process, Acta Biomater. 6 (2010) 3640-8.

[35] D. Robert, D. Fayol, C. Le Visage, G. Frasca, S. Brule, C. Menager, F. Gazeau, D. Letourneur, C. Wilhelm, Magnetic micro-manipulations to probe the local physical properties of porous scaffolds and to confine stem cells, Biomaterials. 31 (2010) 1586-95.

[36] R. Massard, E. Dubois, V. Cabuil, E. Hasmonay, Preparation and properties of monodisperse magnetic fluids, J Magn Magn Mater. 149 (1995) 1-5.

[37] D. Fayol, N. Luciani, L. Lartigue, F. Gazeau, C. Wilhelm, Managing magnetic nanoparticle aggregation and cellular uptake: a precondition for efficient stem-cell differentiation and MRI tracking, Adv Healthc Mater. 2 (2013) 313-25.

[38] M. Lavergne, M. Derkaoui, C. Delmau, D. Letourneur, G. Uzan, C. Le Visage, Porous polysaccharide-based scaffolds for human endothelial progenitor cells, Macromol Biosci. 12 (2012) 901-10.

[39] B. Johnstone, T.M. Hering, A.I. Caplan, V.M. Goldberg, J.U. Yoo, In vitro chondrogenesis of bone marrow-derived mesenchymal progenitor cells, Exp Cell Res. 238 (1998) 265-72.

[40] c.e. draper, t.f. besier, g.e. gold, m. fredericson, a. fiene, g.s. beaupre, s.l. delp, Is cartilage thickness different in young subjects with and without patellofemoral pain?, Osteoarthritis Cartilage. 14 (2006) 931-937.

[41] S.E. Bulman, C.M. Coleman, J.M. Murphy, N. Medcalf, A.E. Ryan, F. Barry, Pullulan: a new cytoadhesive for cell-mediated cartilage repair, Stem Cell Res Ther. 6 (2015) 34. 
[42] J. Zeltinger, J.K. Sherwood, D.A. Graham, R. Mueller, L.G. Griffith, Effect of pore size and void fraction on cellular adhesion, proliferation, and matrix deposition, Tissue Eng. 7 (2001) 557-72.

[43] K.F. Leong, C.M. Cheah, C.K. Chua, Solid freeform fabrication of three-dimensional scaffolds for engineering replacement tissues and organs, Biomaterials. 24 (2003) 2363-78.

[44] T. Yoshikawa, H. Ohgushi, S. Tamai, Intermediate bone forming capability of prefabricated osteogenic hydroxyapatite, Journal of biomedical materials research. 32 (1996) 481-492.

[45] S. Saini, T.M. Wick, Concentric cylinder bioreactor for production of tissue engineered cartilage: effect of seeding density and hydrodynamic loading on construct development, Biotechnol Prog. 19 (2003) 510-21.

[46] A. Purnama, R. Aid-Launais, O. Haddad, M. Maire, D. Mantovani, D. Letourneur, H. Hlawaty, C. Le Visage, Fucoidan in a 3D scaffold interacts with vascular endothelial growth factor and promotes neovascularization in mice, Drug Deliv Transl Res. 5 (2015) 187-97.

[47] C. Le Visage, O. Gournay, N. Benguirat, S. Hamidi, L. Chaussumier, N. Mougenot, J.A. Flanders, R. Isnard, J.B. Michel, S. Hatem, D. Letourneur, F. Norol, Mesenchymal stem cell delivery into rat infarcted myocardium using a porous polysaccharide-based scaffold: a quantitative comparison with endocardial injection, Tissue Eng Part A. 18 (2012) 35-44.

[48] R. Di Corato, F. Gazeau, C. Le Visage, D. Fayol, P. Levitz, F. Lux, D. Letourneur, N. Luciani, O. Tillement, C. Wilhelm, High-resolution cellular MRI: gadolinium and iron oxide nanoparticles for in-depth dual-cell imaging of engineered tissue constructs, ACS Nano. 7 (2013) 7500-12.

[49] M. Levy, N. Luciani, D. Alloyeau, D. Elgrabli, V. Deveaux, C. Pechoux, S. Chat, G. Wang, N. Vats, F. Gendron, C. Factor, S. Lotersztajn, A. Luciani, C. Wilhelm, F. Gazeau, Long term in vivo biotransformation of iron oxide nanoparticles, Biomaterials. 32 (2011) 3988-99.

[50] J. Kolosnjaj-Tabi, Y. Javed, L. Lartigue, J. Volatron, D. Elgrabli, I. Marangon, G. Pugliese, B. Caron, A. Figuerola, N. Luciani, T. Pellegrino, D. Alloyeau, F. Gazeau, The One Year Fate of Iron Oxide Coated Gold Nanoparticles in Mice, ACS Nano. (2015).

[51] K. Shimizu, A. Ito, H. Honda, Mag-seeding of rat bone marrow stromal cells into porous hydroxyapatite scaffolds for bone tissue engineering, J Biosci Bioeng. 104 (2007) 171-7.

[52] I. Martin, M. Jakob, D. Schafer, W. Dick, G. Spagnoli, M. Heberer, Quantitative analysis of gene expression in human articular cartilage from normal and osteoarthritic joints, Osteoarthritis Cartilage. 9 (2001) 112-8.

[53] E.H. Lim, J.P. Sardinha, S. Myers, Nanotechnology biomimetic cartilage regenerative scaffolds, Arch Plast Surg. 41 (2014) 231-40.

[54] R.M. Schulz, A. Bader, Cartilage tissue engineering and bioreactor systems for the cultivation and stimulation of chondrocytes, Eur Biophys J. 36 (2007) 539-68.

[55] O. Antipova, J.P. Orgel, In situ D-periodic molecular structure of type II collagen, J Biol Chem. 285 (2010) 7087-96.

[56] K. Blumbach, Y.M. Bastiaansen-Jenniskens, J. DeGroot, M. Paulsson, G.J. van Osch, F. Zaucke, Combined role of type IX collagen and cartilage oligomeric matrix protein in cartilage matrix assembly: cartilage oligomeric matrix protein counteracts type IX collageninduced limitation of cartilage collagen fibril growth in mouse chondrocyte cultures, Arthritis Rheum. 60 (2009) 3676-85.

[57] P. Garnero, J.C. Rousseau, P.D. Delmas, Molecular basis and clinical use of biochemical markers of bone, cartilage, and synovium in joint diseases, Arthritis Rheum. 43 (2000) 95368. 
[58] M. Crnkic, B. Mansson, L. Larsson, P. Geborek, D. Heinegard, T. Saxne, Serum cartilage oligomeric matrix protein (COMP) decreases in rheumatoid arthritis patients treated with infliximab or etanercept, Arthritis Res Ther. 5 (2003) R181-5.

[59] A. Cheng, T.E. Hardingham, S.J. Kimber, Generating cartilage repair from pluripotent stem cells, Tissue Eng Part B Rev. 20 (2014) 257-66.

[60] G. Shen, The role of type $X$ collagen in facilitating and regulating endochondral ossification of articular cartilage, Orthod Craniofac Res. 8 (2005) 11-7.

[61] J. Malda, D.E. Martens, J. Tramper, C.A. van Blitterswijk, J. Riesle, Cartilage tissue engineering: controversy in the effect of oxygen, Crit Rev Biotechnol. 23 (2003) 175-94.

[62] A.B. Adesida, A. Mulet-Sierra, N.M. Jomha, Hypoxia mediated isolation and expansion enhances the chondrogenic capacity of bone marrow mesenchymal stromal cells, Stem Cell Res Ther. 3 (2012) 9.

[63] S. Portron, V. Hivernaud, C. Merceron, J. Lesoeur, M. Masson, O. Gauthier, C. Vinatier, L. Beck, J. Guicheux, Inverse regulation of early and late chondrogenic differentiation by oxygen tension provides cues for stem cell-based cartilage tissue engineering, Cell Physiol Biochem. 35 (2015) 841-57.

[64] T.D. Bornes, N.M. Jomha, A. Mulet-Sierra, A.B. Adesida, Hypoxic culture of bone marrow-derived mesenchymal stromal stem cells differentially enhances in vitro chondrogenesis within cell-seeded collagen and hyaluronic acid porous scaffolds, Stem Cell Res Ther. 6 (2015) 84.

[65] N.V. Ghone, W.L. Grayson, Recapitulation of mesenchymal condensation enhances in vitro chondrogenesis of human mesenchymal stem cells, J Cell Physiol. 227 (2012) 3701-8.

[66] H.H. Lee, C.C. Chang, M.J. Shieh, J.P. Wang, Y.T. Chen, T.H. Young, S.C. Hung, Hypoxia enhances chondrogenesis and prevents terminal differentiation through PI3K/Akt/FoxO dependent anti-apoptotic effect, Sci Rep. 3 (2013) 2683.

[67] S. Rampersad, J.C. Ruiz, A. Petit, S. Lerouge, J. Antoniou, M.R. Wertheimer, F. Mwale, Stem cells, nitrogen-rich plasma-polymerized culture surfaces, and type $\mathrm{X}$ collagen suppression, Tissue Eng Part A. 17 (2011) 2551-60.

[68] B.A. Byers, R.L. Mauck, I.E. Chiang, R.S. Tuan, Transient exposure to transforming growth factor beta 3 under serum-free conditions enhances the biomechanical and biochemical maturation of tissue-engineered cartilage, Tissue Eng Part A. 14 (2008) 1821-34.

[69] I. Takahashi, G.H. Nuckolls, K. Takahashi, O. Tanaka, I. Semba, R. Dashner, L. Shum, H.C. Slavkin, Compressive force promotes sox9, type II collagen and aggrecan and inhibits IL-1beta expression resulting in chondrogenesis in mouse embryonic limb bud mesenchymal cells, J Cell Sci. 111 ( Pt 14) (1998) 2067-76.

[70] R.L. Mauck, M.A. Soltz, C.C. Wang, D.D. Wong, P.H. Chao, W.B. Valhmu, C.T. Hung, G.A. Ateshian, Functional tissue engineering of articular cartilage through dynamic loading of chondrocyte-seeded agarose gels, J Biomech Eng. 122 (2000) 252-60.

[71] G. Vunjak-Novakovic, I. Martin, B. Obradovic, S. Treppo, A.J. Grodzinsky, R. Langer, L.E. Freed, Bioreactor cultivation conditions modulate the composition and mechanical properties of tissue-engineered cartilage, J Orthop Res. 17 (1999) 130-8.

[72] C.J. O'Conor, N. Case, F. Guilak, Mechanical regulation of chondrogenesis, Stem Cell Res Ther. 4 (2013) 61.

[73] J.J. Campbell, D.A. Lee, D.L. Bader, Dynamic compressive strain influences chondrogenic gene expression in human mesenchymal stem cells, Biorheology. 43 (2006) 455-70.

[74] S.D. Waldman, D.C. Couto, M.D. Grynpas, R.M. Pilliar, R.A. Kandel, Multi-axial mechanical stimulation of tissue engineered cartilage: review, Eur Cell Mater. 13 (2007) 6673; discussion 73-4. 
[75] M.A. Wimmer, S. Grad, T. Kaup, M. Hanni, E. Schneider, S. Gogolewski, M. Alini, Tribology approach to the engineering and study of articular cartilage, Tissue Eng. 10 (2004) 1436-45.

[76] S. Grad, D. Eglin, M. Alini, M.J. Stoddart, Physical stimulation of chondrogenic cells in vitro: a review, Clin Orthop Relat Res. 469 (2011) 2764-72.

[77] N.C. Foster, J.R. Henstock, Y. Reinwald, A.J. El Haj, Dynamic 3D culture: models of chondrogenesis and endochondral ossification, Birth Defects Res C Embryo Today. 105 (2015) 19-33.

[78] Y. Martin, P. Vermette, Bioreactors for tissue mass culture: design, characterization, and recent advances, Biomaterials. 26 (2005) 7481-503. 